\title{
Programming of Stress-Sensitive Neurons and Circuits by Early-Life Experiences
}

\author{
Jessica L. Bolton, Annabel Katherine Short, Kristina A. Simeone, Jennifer Daglian \\ and Tallie Z. Baram* \\ Departments of Pediatrics, Anatomy/Neurobiology, Neurology, University of California, Irvine, Irvine, CA, United States
}

Early-life experiences influence brain structure and function long-term, contributing to resilience or vulnerability to stress and stress-related disorders. Therefore, understanding the mechanisms by which early-life experiences program specific brain cells and circuits to shape life-long cognitive and emotional functions is crucial. We identify the population of corticotropin-releasing hormone $(\mathrm{CRH})$-expressing neurons in the hypothalamic paraventricular nucleus (PVN) as a key, early target of early-life experiences. Adverse experiences increase excitatory neurotransmission onto PVN CRH cells, whereas optimal experiences, such as augmented and predictable maternal care, reduce the number and function of glutamatergic inputs onto this cell population. Altered synaptic neurotransmission is sufficient to initiate large-scale, enduring epigenetic re-programming within $\mathrm{CRH}$-expressing neurons, associated with stress resilience and additional cognitive and emotional outcomes. Thus, the mechanisms by which early-life

OPEN ACCESS

Edited by: Kevin G. Bath,

Brown University, United States

Reviewed by: Travis D. Goode, Harvard University, United States Valery Grinevich, German Cancer Research Center (DKFZ), Germany

*Correspondence: Tallie Z. Baram tallie@uci.edu

Received: 19 December 2018 Accepted: 04 February 2019 Published: 18 February 2019

Citation:

Bolton JL, Short AK, Simeone KA, Daglian J and Baram TZ (2019) Programming of Stress-Sensitive Neurons and Circuits by Early-Life Experiences. Front. Behav. Neurosci. 13:30. doi: 10.3389/fnbeh.2019.00030 experiences influence the brain provide tractable targets for intervention.

Keywords: CRH (corticotropin-releasing hormone), circuits, NRSF (neuron-restrictive silencer factor), limited bedding and nesting, brown adipose tissue, anhedonia

\section{INTRODUCTION}

The origins of mental health outcomes are early in life (Kessler et al., 2005; Insel, 2009). Genetic factors and early-life experiences, both adverse and nurturing, interact to modulate vulnerability and resilience to disease (Insel, 2009; Bale et al., 2010; Fox et al., 2010; Gunnar, 2010; Juul et al., 2011; Bale, 2015). There is now a large body of evidence in humans associating early-life adversity with emotional and cognitive disorders later in life (e.g., Bremner et al., 1993; Brown et al., 1995; Kaplan et al., 2001; Eriksson et al., 2014). To elucidate causal and mechanistic relationships between early-life experiences and later mental health, nonhuman primate (Koch et al., 2014; Wakeford et al., 2018) and rodent models have been utilized, specifically paradigms of adverse vs. optimal early-life experiences, which provoke cognitive and emotional changes relevant to human health (Weaver et al., 2004; Molet et al., 2014; Chen and Baram, 2016; Krugers et al., 2017; Walker et al., 2017; van Bodegom et al., 2017). Here, we discuss these animal models and provide new information on two major categories of changes in brain development that underlie risk vs. resilience to mental disorders: (1) circuit development; and (2) epigenetic alterations, as well as their mechanisms.

\section{EARLY-LIFE ADVERSITY}

Experimental model studies, together with human studies, have found that maternal input has perhaps the most significant influence on the environment experienced during development 
(Bowlby, 1950; Seay et al., 1962; Baram et al., 2012; RincónCortés and Sullivan, 2014; Kundakovic and Champagne, 2015). Thus, most animal models of early-life adversity have manipulated maternal interaction with pups, disrupting either the quantity or quality of maternal care early in life (for recent reviews see Molet et al., 2014; Walker et al., 2017; van Bodegom et al., 2017). This typically involves maternal separation or simulated poverty; in this perspective we shall focus on the latter. To simulate poverty, nesting and bedding materials in the cage are restricted (limited bedding and nesting: LBN) during postnatal days (P)2-9 (Figures 1A,B; Gilles et al., 1996; Molet et al., 2014; Naninck et al., 2014). This manipulation reliably and reproducibly causes fragmented and unpredictable maternal behaviors towards the pups (Molet et al., 2016a). Notably, the overall duration or quality of the nurturing behaviors of the dams are minimally altered; it is the patterns of maternal care that are disrupted (Ivy et al., 2008; Rice et al., 2008; Molet et al., 2016a; Walker et al., 2017). This fragmented maternal care causes chronic, unpredictable and uncontrollable "emotional stress" in the pups (Gilles et al., 1996; Ivy et al., 2008; Rice et al., 2008; Moriceau et al., 2009; Wang et al., 2011; Molet et al., 2014; Naninck et al., 2014). The stress is apparent in persistent elevations of plasma corticosterone and adrenal hypertrophy, and is associated with emotional and cognitive problems in adulthood (Brunson et al., 2005; Rice et al., 2008; Molet et al., 2016b). Notably, children that experience early-life adversity have an increased risk of developing similar difficulties, such as memory deficits, self-control issues, and internalizing disorders (Davis et al., 2017; Glynn et al., 2018).

\section{Circuit Development}

Consistent with behavioral deficits, early-life adversity is associated with alterations in brain connectivity in humans, as apparent from neuroimaging studies (Posner et al., 2016; Fareri et al., 2017; Kopala-Sibley et al., 2018). Neuroimaging in rodents has identified increased structural connectivity between the medial prefrontal cortex and amygdala in adolescent LBN male rats, in association with anhedonia-like behavior (Bolton et al., 2018a). However, functional resting-state connectivity of amygdala to medial prefrontal cortex is diminished in LBN male rats pre-weaning and in adulthood. This was interpreted as suggesting that neonatal amygdala activation may accelerate the maturation of amygdala to prefrontal cortex projections and impact the functional integrity of such connections (Guadagno et al., 2018). Clearly, additional studies are required to discern how early-life adversity influences amygdala-cortical connectivity.

In experimental models, in addition to neuroimaging, one can assess directly synaptic connectivity via neuroanatomical studies. For example, early-life adversity causes increased excitatory connections onto corticotropin-releasing hormone (CRH)-expressing neurons in the paraventricular nucleus of the hypothalamus (PVH; Gunn et al., 2013). These neurons play a critical role in the stress response (Deussing and Chen, 2018), and thus their increased excitatory innervation may promote prolonged responses to stress in LBN animals (Gilles et al., 1996).

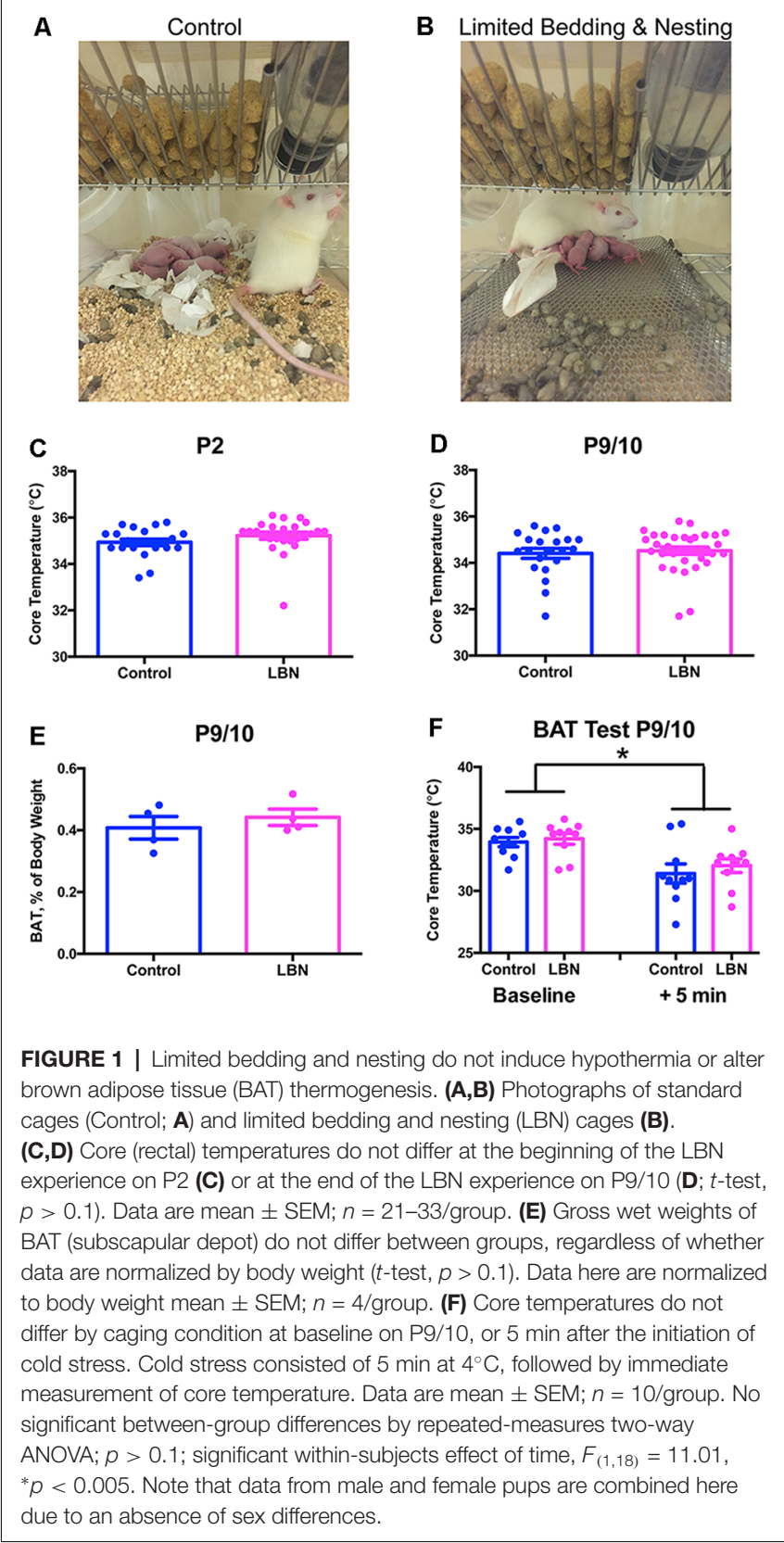

Conversely, hippocampal regions exhibit reduced dendritic arborization and synaptic connections in LBN rats, which has been linked to adversity-induced memory deficits throughout life (Brunson et al., 2005; Ivy et al., 2010; Molet et al., 2016b). Thus, the effects of early-life adversity are brain region-dependent.

It is important to note that a specific stress-related consequence never stems exclusively from one single neuropeptide, but rather a combined interaction of many different neurotransmitter and/or neuropeptide systems. For example, oxytocin is a hypothalamic neuropeptide that has been implicated as a key molecule in the regulation of fear and anxiety, and has been shown to have effects on other neurotransmitter systems. Specifically, early-life adversity can impact oxytocin receptor expression of adult animals (Neumann and Slattery, 
2016), and oxytocin has been shown to regulate CRH expression within the PVN (Jurek et al., 2015). Here, due to the limited scope of this perspective, we focus primarily on the programming of $\mathrm{CRH}$ neurons by early-life experiences.

\section{Epigenetic Alterations}

Long-term phenotypic changes resulting from early-life adversity involve enduring alterations in the expression of important neuronal genes. A large body of work has now shown that early-life adversity is associated with transcriptional changes in both humans (Heim and Binder, 2012; Suderman et al., 2014; Schwaiger et al., 2016) and various rodent models (McClelland et al., 2011; Russo et al., 2012; Lucassen et al., 2013; Nestler, 2014; Szyf et al., 2016; Deussing and Jakovcevski, 2017; Peña et al., 2017; Ross et al., 2017; Gray et al., 2018). Much of the literature has focused on genes and gene families involved directly with stress, such as the glucocorticoid receptor (GR; Weaver et al., 2004; Gray et al., 2017). Early-life adversity decreases expression of GR in the PVN and frontal cortex in LBN rats (Avishai-Eliner et al., 2001), resulting in altered glucocorticoid negative feedback. In addition to GR, changes in Fkbp5 have been reported. Fkbp5 is a co-chaperone protein that binds to cytosolic GR in its inactive state, thus inhibiting GR translocation and function. Genetic polymorphisms of Fkbp5 in humans mediate a gene by environment interaction of childhood abuse and severity of PTSD symptoms later in life (Segman et al., 2005; Binder et al., 2008; Yehuda et al., 2009). Specifically, alleles associated with greater expression or function of Fkbp5, thought to result in GR hypersensitivity, are associated with greater vulnerability to PTSD symptoms after childhood abuse (Binder et al., 2008).

$\mathrm{CRH}$ is a key stress-related neuronal gene shown to be regulated by early-life adversity. Acutely after early-life adversity, CRH levels in the PVN are reduced in LBN rats and mice (Avishai-Eliner et al., 2001; Rice et al., 2008), likely as a result of depletion of CRH stores by the enhanced release of the peptide during the adversity period (Ma and Lightman, 1998). Over the past decade, the expression and function of $\mathrm{CRH}$ in brain regions outside the PVN has been established (Chen et al., 2001; Regev et al., 2011, 2012; Deussing and Chen, 2018). Notably, early-life adversity influences $\mathrm{CRH}$ expression in several of these regions. $\mathrm{CRH}$ is upregulated in the central nucleus of the amygdala (ACe; Dubé et al., 2015) and hippocampus of LBN rats (Brunson et al., 2001; Ivy et al., 2010). CRH is required for normal pruning and refinement of dendritic trees and synapses (Chen et al., 2004). In addition, excessive levels of $\mathrm{CRH}$ have been linked with aberrant neuronal structure and function (Chen et al., 2004; Ivy et al., 2010; Curran et al., 2017; Gunn and Baram, 2017).

Early adversity-induced changes in gene expression can be lifelong because of epigenetic processes involving master regulators, such as GR (Joëls and Baram, 2009; Schmidt et al., 2013; McEwen et al., 2016; Gray et al., 2017; van Bodegom et al., 2017). GR acts as a transcription factor along with several interacting proteins (Binder, 2009; Klengel and Binder, 2015; $\mathrm{Xu}$ et al., 2017; Ke et al., 2018) to modulate gene expression long-term and influence neuronal function (Daskalakis et al., 2015). Notably, recent mechanistic studies employing LBN (Arp et al., 2016; Lesuis et al., 2018) or maternal deprivation (Loi et al., 2017) have now directly confirmed a key role for GR in mediating the effects of early-life adversity on long-term brain function.

In addition to GR, our recent work has revealed an unexpected regulator of long-term changes in gene expression provoked by early-life adversity, the transcriptional repressor neuron-restrictive silencer factor (NRSF; Schulmann et al., 2018). This transcription factor has long been known to regulate CRH expression (Seth and Majzoub, 2001). Recently, RNA-seq detected transcriptome-wide changes in the dorsal hippocampus of LBN rats; surprisingly, most genes were downregulated. Upstream analysis of target enrichment identified GR and NRSF as major regulators of gene changes, and NRSF in particular was primarily enriched among downregulated neuronal genes. Notably, inhibition of NRSF binding to chromatin via intracerebroventricular (i.c.v.)-infused decoy oligodeoxynucleotides shortly after early adversity prevented the development of cognitive deficits in LBN rats (Schulmann et al., 2018). Thus, these data implicate NRSF-regulated gene networks in the orchestrated transcriptional programs required for the maturation of spatial memory networks, as well as in the maladaptive silencing of key neuronal genes following early-life adversity.

\section{OPTIMAL EARLY-LIFE EXPERIENCES}

Important biological phenomena run along a spectrum. If unpredictable maternal care provokes long-term vulnerability, then highly predictable patterns of maternal-derived sensory signals to the developing brain should promote cognitive and emotional resilience long-term. Animal models of optimal, predictable early-life experience, though not as widely studied, include those that apply the handling paradigm advanced by Levine and colleagues (Levine, 1957; Plotsky and Meaney, 1993; Francis and Meaney, 1999; Korosi and Baram, 2009). This involves a brief (15-min) daily separation of rat pups from the mother during the 1st weeks of life. The timing of these bouts of separation is critical, and brief separations will promote increased, predictable sensory input (e.g., licking and grooming) to the pups upon reunion with their mothers (Liu et al., 1997; Fenoglio et al., 2006; Korosi et al., 2010). The recurrent, predictable maternal signals lead to increased resilience to depressive- and anxiety-like behaviors and improved learning and memory (Weaver et al., 2004; Fenoglio et al., 2005, 2006; Champagne, 2008; Korosi and Baram, 2009; Korosi et al., 2010; Singh-Taylor et al., 2018). The mechanisms by which handling improves emotional and cognitive outcomes is not fully understood. Separating pups from their mothers by itself is insufficient. In addition, a single day of handling or repeated but irregular handling are insufficient to promote the molecular and behavioral outcomes (Fenoglio et al., 2006). It thus appears that recurrent and predictable bouts of maternal care, occurring after the brief separations (typically in the same circadian phase), drive the structural and functional brain alterations that promote resilience (Fenoglio et al., 2006; Karsten and Baram, 2013; Davis et al., 2017). 


\section{Circuit Development}

The behavioral resilience may result from the influence of optimal early-life experiences on the maturation of stressrelated circuits. For example, predictable maternal care results in decreased excitatory synapses onto $\mathrm{CRH}$ neurons in the PVN - the exact opposite of the effect of unpredictable maternal care discussed above (Korosi et al., 2010). This decreased synaptic innervation was associated with a diminished frequency of excitatory synaptic currents onto $\mathrm{CRH}$ neurons in the PVN, consistent with the observed later-life decrease in stress responsiveness (Korosi et al., 2010; Singh-Taylor et al., 2018). Augmented maternal care further altered the development of other neural systems. For example, the postnatal assembly of preautonomic emotional motor circuits, such as cortical and limbic projections from the bed nucleus of the stria terminalis (BNST), ACe, and visceral cortex to autonomic nuclei, was diminished in animals experiencing neonatal handling (Card et al., 2005). Conversely, in the hippocampus, pyramidal neurons had greater spine density and dendritic complexity, along with enhanced functional synaptic plasticity, in rats that experienced augmented maternal care (Champagne et al., 2008). This result contrasts with the impoverished dendritic trees in rats that experienced fragmented, unpredictable maternal care (Brunson et al., 2005; Ivy et al., 2010; Molet et al., 2016b).

\section{Epigenetic Alterations}

Long-term changes in gene expression may underlie the resilience observed after optimal early-life experiences. For example, in the hippocampus, GR density was increased in adult rats that experienced neonatal handling (Meaney et al., 1985; Liu et al., 1997). In the PVN, a major change induced by augmented, predictable maternal care was decreased $\mathrm{CRH}$ expression by P9, prior to the GR change (Plotsky and Meaney, 1993; Liu et al., 1997; Fenoglio et al., 2004, 2005). Mechanistic studies have revealed that reduction of excitatory neurotransmission onto PVN CRH neurons is sufficient to diminish their expression of $\mathrm{CRH}$, among other important neuronal genes related to synaptic function (Singh-Taylor et al., 2018). These alterations in gene expression following optimal early-life experiences can be maintained long-term by epigenetic mechanisms. Largescale changes in repressive histone modifications of neuronal genes like CRH were initiated by increases in function of the transcriptional repressor, NRSF (Singh-Taylor et al., 2018), the same transcription factor that is implicated in programming LBN-induced cognitive vulnerabilities (Schulmann et al., 2018). These results provide a causal link between neonatal experience, synaptic refinement and induction of epigenetic processes within specific neuronal populations.

\section{HOW DOES EARLY-LIFE ADVERSITY INFLUENCE THE MATURATION OF THE BRAIN?}

Early-life adversity consists of both physical and emotional components. Physical stress may include hunger or cold, whereas emotional aspects may involve absence or poor care by a stressed parent. In humans, the relative importance of emotional adversity is apparent from comparing outcomes in developing countries, where poverty is almost universal but family structure is stable and nurturing, to outcomes in low-socioeconomic status enclaves in developed countries (Hackman et al., 2010; Crookston et al., 2014; Agidew and Singh, 2018). In contrast, in orphanages where physical wellbeing (i.e., nutrition, shelter) is maintained, but parental care is lacking (and care-giving in general is scarce), emotional and cognitive outcomes of the orphans have been highly deficient (Pollak et al., 2010; Nelson et al., 2011). Both of these scenarios indicate that it is not the physical, but largely emotional, adversity that shapes mental health trajectories.

In our animal model of early-life adversity, we sought to discern the relative roles of physical and emotional adversity in the outcomes discussed above. Physical stress clearly exists in the paradigm (i.e., elevated corticosterone, increased adrenal weights; Brunson et al., 2005; Rice et al., 2008). However, other potential measures of physical stress are absent. For example, cold stress is not prominent: pups do not experience hypothermia in the LBN cages. Core temperatures of control vs. LBN pups
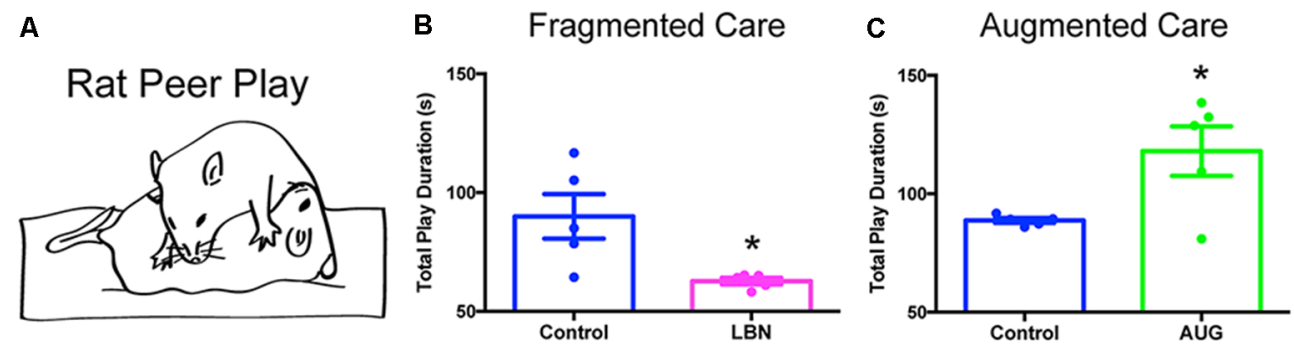

FIGURE 2 | Early-life experiences bidirectionally modulate peer-play behavior. (A) Schematic of an example rat peer-play posture, known as pinning. The total play duration graphed in $\mathbf{B}, \mathbf{C})$ consists of the summed duration in seconds of all play behaviors, including pinning, pouncing, chasing/following, boxing, and kicking, that a late-adolescent male experimental rat performs, directed toward a juvenile same-sex conspecific, during a 10-min test of social interaction in an open field.

(B) Fragmented, unpredictable maternal care (LBN) provokes anhedonia, shown here as decreased peer play in a test of social interaction. Data are mean \pm SEM; $n=5 /$ group; $t$-test with Welch's correction for unequal variance, $t_{(4.169)}=2.879,{ }^{*} p<0.05$. (C) Augmented, predictable maternal care (AUG) results in increased peer play in late adolescence. Data are mean \pm SEM; $n=5$ /group; $t$-test with Welch's correction for unequal variance, $t_{(4.070)}=2.788,{ }^{*} p<0.05$. 
are indistinguishable at multiple time points during $\mathrm{P} 2-10$ (Figures 1C,D). To consider the possibility that LBN pups might engage their brown adipose tissue (BAT) stores to maintain core temperature and avoid hypothermia, we assessed brown adipose amounts and utilization. The data did not support this hypothesis: a BAT activation test of thermogenesis (Dawkins and Hull, 1964; Himms-Hagen, 1990; Akana and Dallman, 1997) did not reveal any differences between groups, and gross BAT weights did not differ with LBN conditions (Figures 1E,F). This result was not surprising, because the total time the mother spends with her pups is comparable in simulated poverty (LBN) cages and those with a full complement of bedding and nesting material (Molet et al., 2016a). In contrast, the patterns of maternal care are altered, and care is fragmented and unpredictable. It is thus likely that these chaotic maternal sensory signals to the developing brain during a sensitive period provoke the adverse outcomes (Baram et al., 2012; Chen and Baram, 2016; Davis et al., 2017; Walker et al., 2017).

\section{HOW DO OPTIMAL EARLY-LIFE EXPERIENCES INFLUENCE BRAIN MATURATION?}

Resilience-promoting experiences such as predictable, recurrent maternal sensory signals engage emotion-related circuity. Fos activation of the ACe and BNST, both upstream of PVN CRH neurons, was noted following a single bout of handling and augmented maternal care, but this was insufficient to repress CRH expression in the PVN (Fenoglio et al., 2006). Notably, a week of recurrent daily bouts of augmented maternal care activated the ACe and BNST, as well as the paraventricular nucleus of the thalamus (PVT). The PVT is considered a "stress-memory" center of the brain (Bhatnagar and Dallman, 1998; Bhatnagar et al., 2000). This combined output to PVN $\mathrm{CRH}$ neurons in concert with recurrent handling resulted in enduring suppression of $\mathrm{CRH}$ expression in these neurons (Fenoglio et al., 2006; Karsten and Baram, 2013). Because neurons that "fire together, wire together," it is likely that these differential neuronal network activation patterns influence emotion-related circuit development and underlie the long-term resilience resulting from predictable maternal sensory signals.

Although less well-explored in this context, reward/pleasure circuits may be engaged by resilience-promoting experiences. Notably, there is evidence that predictable sequences of events activate the reward system (Berns et al., 2001; Rutledge et al., 2014). The dopaminergic reward system is not fully developed until the third postnatal week in rodents (Voorn et al., 1988) and is sensitive to alterations in early-life experiences (Ventura et al., 2013; Peña et al., 2014). Therefore, in analogy to the modulation of visual, auditory, and motor circuit development by visual, auditory, and sensory signals, we speculate that predictable

\section{REFERENCES}

Agidew, A. A., and Singh, K. N. (2018). Determinants of food insecurity in the rural farm households in South Wollo Zone of Ethiopia: the case of the patterns of maternal care provide crucial cues for maturation of the reward/pleasure system. Conversely, unpredictable and fragmented maternal care may result in aberrant maturation of the reward/pleasure circuitry. In support of this notion, LBN has been shown to provoke anhedonia, manifest as reduced sucrose preference, peer play, and cocaine craving in adolescent male rats, accompanied by aberrant connectivity between stress- and reward-related brain regions (Bolton et al., 2018a,b; Figures 2A,B). In turn, preliminary data suggest that predictable, recurrent maternal care results in increased peer play in adolescent male rats (Figure 2C). Thus, patterns of maternal sensory signals may exert bidirectional influence over the maturation of the reward/pleasure system-a hypothesis that warrants further exploration.

\section{CONCLUSIONS}

In sum, early-life experiences influence an individual's risk vs. resilience for emotional and cognitive disorders. The biological processes underlying these profound and enduring effects include influences on circuit development, associated with epigenetic changes. CRH-expressing cells in the neonatal hypothalamus are a key, early target of these experiencedependent mechanisms. Thus, these and other, yet undiscovered, mechanisms by which early-life experiences influence the brain provide tractable targets for intervention.

\section{DATA AVAILABILITY}

All datasets generated for this study are included in the manuscript.

\section{ETHICS STATEMENT}

This study was carried out in accordance with the recommendations of the National Institutes of Health. The protocol was approved by the UC Irvine Animal Care and Use Committee.

\section{AUTHOR CONTRIBUTIONS}

TB designed the experiments. JB, KS, and JD performed the experiments and analyzed the data. TB, JB, and AS wrote the article.

\section{FUNDING}

This work was supported by National Institutes of Health (NIH) grants P50 MH096889 and MH073136 and the Hewitt Foundation for Biomedical Research. The funders did not play any role in the design or interpretation of experiments.

Teleyayen sub-watershed. Agric. Food Econ. 6:10. doi: 10.1186/s40100-018 0106-4

Akana, S. F., and Dallman, M. F. (1997). Chronic cold in adrenalectomized, corticosterone (B)-treated rats: facilitated corticotropin responses to 
acute restraint emerge as B increases. Endocrinology 138, 3249-3258. doi: 10.1210/endo.138.8.5291

Arp, J. M., ter Horst, J. P., Loi, M., den Blaauwen, J., Bangert, E., Fernández, G., et al. (2016). Blocking glucocorticoid receptors at adolescent age prevents enhanced freezing between repeated cue-exposures after conditioned fear in adult mice raised under chronic early life stress. Neurobiol. Learn. Mem. 133, 30-38. doi: 10.1016/j.nlm.2016.05.009

Avishai-Eliner, S., Gilles, E. E., Eghbal-Ahmadi, M., Bar-El, Y., and Baram, T. Z. (2001). Altered regulation of gene and protein expression of hypothalamicpituitary-adrenal axis components in an immature rat model of chronic stress. J. Neuroendocrinol. 13, 799-807. doi: 10.1046/j.1365-2826.2001.00698.x

Bale, T. L. (2015). Epigenetic and transgenerational reprogramming of brain development. Nat. Rev. Neurosci. 16, 332-344. doi: 10.1038/nrn3818

Bale, T. L., Baram, T. Z., Brown, A. S., Goldstein, J. M., Insel, T. R., McCarthy, M. M., et al. (2010). Early life programming and neurodevelopmental disorders. Biol. Psychiatry 68, 314-319. doi: 10.1016/j. biopsych.2010.05.028

Baram, T. Z., Davis, E. P., Obenaus, A., Sandman, C. A., Small, S. L., Solodkin, A., et al. (2012). Fragmentation and unpredictability of early-life experience in mental disorders. Am. J. Psychiatry 169, 907-915. doi: 10.1176/appi.ajp.2012. 11091347

Berns, G. S., McClure, S. M., Pagnoni, G., and Montague, P. R. (2001). Predictability modulates human brain response to reward. J. Neurosci. 21, 2793-2798. doi: 10.1523/jneurosci.21-08-02793.2001

Bhatnagar, S., and Dallman, M. (1998). Neuroanatomical basis for facilitation of hypothalamic-pituitary-adrenal responses to a novel stressor after chronic stress. Neuroscience 84, 1025-1039. doi: 10.1016/s0306-4522(97)00577-0

Bhatnagar, S., Viau, V., Chu, A., Soriano, L., Meijer, O. C., and Dallman, M. F. (2000). A cholecystokinin-mediated pathway to the paraventricular thalamus is recruited in chronically stressed rats and regulates hypothalamic-pituitaryadrenal function. J. Neurosci. 20, 5564-5573. doi: 10.1523/jneurosci.20-1405564.2000

Binder, E. B. (2009). The role of FKBP5, a co-chaperone of the glucocorticoid receptor in the pathogenesis and therapy of affective and anxiety disorders. Psychoneuroendocrinology 34, S186-S195. doi: 10.1016/j.psyneuen.2009.05.021

Binder, E. B., Bradley, R. G., Liu, W., Epstein, M. P., Deveau, T. C., Mercer, K. B., et al. (2008). Association of FKBP5 polymorphisms and childhood abuse with risk of posttraumatic stress disorder symptoms in adults. JAMA 299, 1291-1305. doi: 10.1001/jama.299.11.1291

Bolton, J. L., Molet, J., Regev, L., Chen, Y., Rismanchi, N., Haddad, E., et al. (2018a). Anhedonia following early-life adversity involves aberrant interaction of reward and anxiety circuits and is reversed by partial silencing of amygdala corticotropin-releasing hormone gene. Biol. Psychiatry 83, 137-147. doi: 10.1016/j.biopsych.2017.08.023

Bolton, J. L., Ruiz, C. M., Rismanchi, N., Sanchez, G. A., Castillo, E., Huang, J., et al. (2018b). Early-life adversity facilitates acquisition of cocaine self-administration and induces persistent anhedonia. Neurobiol. Stress 8, 57-67. doi: 10.1016/j.ynstr.2018.01.002

Bowlby, J. (1950). Research into the origins of delinquent behaviour. Br. Med. J. 1, 570-573. doi: 10.1136/bmj.1.4653.570

Bremner, J. D., Southwick, S. M., Johnson, D. R., Yehuda, R., and Charney, D. S. (1993). Childhood physical abuse and combat-related posttraumatic stress disorder in Vietnam veterans. Am. J. Psychiatry 150, 235-239. doi: 10.1176/ajp. 150.2.235

Brown, A. S., Susser, E. S., Lin, S. P., Neugebauer, R., and Gorman, J. M. (1995). Increased risk of affective disorders in males after second trimester prenatal exposure to the Dutch hunger winter of 1944-45. Br. J. Psychiatry 166, 601-606. doi: 10.1192/bjp.166.5.601

Brunson, K. L., Kramár, E., Lin, B., Chen, Y., Colgin, L. L., Yanagihara, T. K., et al. (2005). Mechanisms of late-onset cognitive decline after early-life stress. J. Neurosci. 25, 9328-9338. doi: 10.1523/JNEUROSCI.2281-05.2005

Brunson, K. L., Mariam, E.-A., Bender, R., Chen, Y., and Baram, T. Z. (2001). Long-term, progressive hippocampal cell loss and dysfunction induced by early-life administration of corticotropin-releasing hormone reproduce the effects of early-life stress. Proc. Natl. Acad. Sci. U S A 98, 8856-8861. doi: $10.1073 /$ pnas. 151224898

Card, J. P., Levitt, P., Gluhovsky, M., and Rinaman, L. (2005). Early experience modifies the postnatal assembly of autonomic emotional motor circuits in rats. J. Neurosci. 25, 9102-9111. doi: 10.1523/jneurosci.2345-05.2005
Champagne, F. A. (2008). Epigenetic mechanisms and the transgenerational effects of maternal care. Front. Neuroendocrinol. 29, 386-397. doi: 10.1016/j. yfrne.2008.03.003

Champagne, D. L., Bagot, R. C., van Hasselt, F., Ramakers, G., Meaney, M. J., de Kloet, E. R., et al. (2008). Maternal care and hippocampal plasticity: evidence for experience-dependent structural plasticity, altered synaptic functioning and differential responsiveness to glucocorticoids and stress. J. Neurosci. 28, 6037-6045. doi: 10.1523/JNEUROSCI.0526-08.2008

Chen, Y., and Baram, T. Z. (2016). Toward understanding how early-life stress reprograms cognitive and emotional brain networks. Neuropsychopharmacology 41, 197-206. doi: 10.1038/npp. 2015.181

Chen, Y., Bender, R. A., Brunson, K. L., Pomper, J. K., Grigoriadis, D. E., Wurst, W., et al. (2004). Modulation of dendritic differentiation by corticotropin-releasing factor in the developing hippocampus. Proc. Natl. Acad. Sci. U S A 101, 15782-15787. doi: 10.1073/pnas.04039 75101

Chen, Y., Bender, R. A., Frotscher, M., and Baram, T. Z. (2001). Novel and transient populations of corticotropin-releasing hormone-expressing neurons in developing hippocampus suggest unique functional roles: a quantitative spatiotemporal analysis. J. Neurosci. 21, 7171-7181. doi: 10.1523/jneurosci.2118-07171.2001

Crookston, B. T., Forste, R., McClellan, C., Georgiadis, A., and Heaton, T. B. (2014). Factors associated with cognitive achievement in late childhood and adolescence: the young lives cohort study of children in Ethiopia, India, Peru and Vietnam. BMC Pediatr. 14:253. doi: 10.1186/1471-243114-253

Curran, M. M., Sandman, C. A., Poggi Davis, E., Glynn, L. M., and Baram, T. Z. (2017). Abnormal dendritic maturation of developing cortical neurons exposed to corticotropin releasing hormone (CRH): insights into effects of prenatal adversity? PLoS One 12:e0180311. doi: 10.1371/journal.pone.01 80311

Daskalakis, N. P., De Kloet, E. R., Yehuda, R., Malaspina, D., and Kranz, T. M. (2015). Early life stress effects on glucocorticoid-BDNF interplay in the hippocampus. Front. Mol. Neurosci. 8:68. doi: 10.3389/fnmol.2015. 00068

Davis, E. P., Stout, S. A., Molet, J., Vegetabile, B., Glynn, L. M., Sandman, C. A., et al. (2017). Exposure to unpredictable maternal sensory signals influences cognitive development across species. Proc. Natl. Acad. Sci. U S A 114, 10390-10395. doi: 10.1073/pnas.1703444114

Dawkins, M. J. R., and Hull, D. (1964). Brown adipose tissue and the response of new-born rabbits to cold. J. Physiol. 172, 216-238. doi: 10.1113/jphysiol.1964. sp007414

Deussing, J. M., and Chen, A. (2018). The corticotropin-releasing factor family: physiology of the stress response. Physiol. Rev. 98, 2225-2286. doi: $10.1152 /$ physrev.00042.2017

Deussing, J. M., and Jakovcevski, M. (2017). Histone modifications in major depressive disorder and related rodent models. Adv. Exp. Med. Biol. 978, 169-183. doi: 10.1007/978-3-319-53889-1_9

Dubé, C. M., Molet, J., Singh-Taylor, A., Ivy, A., Maras, P. M., and Baram, T. Z. (2015). Hyper-excitability and epilepsy generated by chronic early-life stress. Neurobiol. Stress 2, 10-19. doi: 10.1016/j.ynstr.2015.03.001

Eriksson, M., Räikkönen, K., and Eriksson, J. G. (2014). Early life stress and later health outcomes-findings from the helsinki birth cohort study. Am. J. Hum. Biol. 26, 111-116. doi: 10.1002/ajhb.22502

Fareri, D. S., Gabard-Durnam, L., Goff, B., Flannery, J., Gee, D. G., Lumian, D. S., et al. (2017). Altered ventral striatal-medial prefrontal cortex resting-state connectivity mediates adolescent social problems after early institutional care. Dev. Psychopathol. 29, 1865-1876. doi: 10.1017/s09545794170 01456

Fenoglio, K. A., Brunson, K. L., Avishai-Eliner, S., Chen, Y., and Baram, T. Z. (2004). Region-specific onset of handling-induced changes in corticotropinreleasing factor and glucocorticoid receptor expression. Endocrinology 145, 2702-2706. doi: 10.1210/en.2004-0111

Fenoglio, K. A., Brunson, K. L., Avishai-Eliner, S., Stone, B. A., Kapadia, B. J., and Baram, T. Z. (2005). Enduring, handling-evoked enhancement of hippocampal memory function and glucocorticoid receptor expression involves activation of the corticotropin-releasing factor type 1 receptor. Endocrinology 146, 4090-4096. doi: 10.1210/en.2004-1285 
Fenoglio, K. A., Chen, Y., and Baram, T. Z. (2006). Neuroplasticity of the hypothalamic-pituitary-adrenal axis early in life requires recurrent recruitment of stress-regulating brain regions. J. Neurosci. 26, 2434-2442. doi: 10.1523/JNEUROSCI.4080-05.2006

Fox, S. E., Levitt, P., and Nelson, C. A. III. (2010). How the timing and quality of early experiences influence the development of brain architecture. Child Dev. 81, 28-40. doi: 10.1111/j.1467-8624.2009.01380.x

Francis, D. D., and Meaney, M. J. (1999). Maternal care and the development of stress responses. Curr. Opin. Neurobiol. 9, 128-134. doi: 10.1016/s09594388(99)80016-6

Gilles, E. E., Schultz, L., and Baram, T. Z. (1996). Abnormal corticosterone regulation in an immature rat model of continuous chronic stress. Pediatr. Neurol. 15, 114-119. doi: 10.1016/0887-8994(96)00153-1

Glynn, L. M., Howland, M. A., Sandman, C. A., Davis, E. P., Phelan, M., Baram, T. Z., et al. (2018). Prenatal maternal mood patterns predict child temperament and adolescent mental health. J. Affect. Disord. 228, 83-90. doi: 10.1016/j.jad.2017.11.065

Gray, J. D., Kogan, J. F., Marrocco, J., and McEwen, B. S. (2017). Genomic and epigenomic mechanisms of glucocorticoids in the brain. Nat. Rev. Endocrinol. 13, 661-673. doi: 10.1038/nrendo.2017.97

Gray, J. D., Rubin, T. G., Kogan, J. F., Marrocco, J., Weidmann, J., Lindkvist, S., et al. (2018). Translational profiling of stress-induced neuroplasticity in the CA3 pyramidal neurons of BDNF Val66Met mice. Mol. Psychiatry 23, 904-913. doi: 10.1038/mp.2016.219

Guadagno, A., Kang, M. S., Devenyi, G. A., Mathieu, A. P., Rosa, P., Chakravarty, M., et al. (2018). Reduced resting-state functional connectivity of the basolateral amygdala to the medial prefrontal cortex in preweaning rats exposed to chronic early-life stress. Brain Struct. Funct. 223, 3711-3729. doi: 10.1007/s00429-018-1720-3

Gunn, B. G., and Baram, T. Z. (2017). Stress and seizures: space, time and hippocampal circuits. Trends Neurosci. 40, 667-679. doi: 10.1016/j.tins.2017. 08.004

Gunn, B. G., Cunningham, L., Cooper, M. A., Corteen, N. L., Seifi, M., Swinny, J. D., et al. (2013). Dysfunctional astrocytic and synaptic regulation of hypothalamic glutamatergic transmission in a mouse model of early-life adversity: relevance to neurosteroids and programming of the stress response. J. Neurosci. 33, 19534-19554. doi: 10.1523/jneurosci.1337-13.2013

Gunnar, M. R. (2010). Reversing the effects of early deprivation after infancy: giving children families may not be enough. Front. Neurosci. 4:170. doi: $10.3389 /$ fnins. 2010.00170

Hackman, D. A., Farah, M. J., and Meaney, M. J. (2010). Socioeconomic status and the brain: mechanistic insights from human and animal research. Nat. Rev. Neurosci. 11, 651-659. doi: 10.1038/nrn2897

Heim, C., and Binder, E. B. (2012). Current research trends in early life stress and depression: review of human studies on sensitive periods, gene-environment interactions, and epigenetics. Exp. Neurol. 233, 102-111. doi: 10.1016/j. expneurol.2011.10.032

Himms-Hagen, J. (1990). Brown adipose tissue thermogenesis: interdisciplinary studies. FASEB J. 4, 2890-2898. doi: 10.1096/fasebj.4.11.2199286

Insel, T. R. (2009). Translating scientific opportunity into public health impact. Arch. Gen. Psychiatry 66, 128-133. doi: 10.1001/archgenpsychiatry.2008.540

Ivy, A. S. S., Brunson, K. L. L., Sandman, C., and Baram, T. Z. Z. (2008). Dysfunctional nurturing behavior in rat dams with limited access to nesting material: a clinically relevant model for early-life stress. Neuroscience 154, 1132-1142. doi: 10.1016/j.neuroscience.2008.04.019

Ivy, A. S., Rex, C. S., Chen, Y., Dubé, C., Maras, P. M., Grigoriadis, D. E., et al. (2010). Hippocampal dysfunction and cognitive impairments provoked by chronic early-life stress involve excessive activation of CRH receptors. J. Neurosci. 30, 13005-13015. doi: 10.1523/jneurosci.1784-10.2010

Joëls, M., and Baram, T. Z. (2009). The neuro-symphony of stress. Nat. Rev. Neurosci. 10, 459-466. doi: 10.1038/nrn2632

Jurek, B., Slattery, D. A., Hiraoka, Y., Liu, Y., Nishimori, K., Aguilera, G., et al. (2015). Oxytocin regulates stress-induced Crf gene transcription through CREB-regulated transcription coactivator 3. J. Neurosci. 35, 12248-12260. doi: 10.1523/jneurosci.1345-14.2015

Juul, S. E., Beyer, R. P., Bammler, T. K., Farin, F. M., and Gleason, C. A. (2011). Effects of neonatal stress and morphine on murine hippocampal gene expression. Pediatr. Res. 69, 285-292. doi: 10.1203/pdr.0b013e31820bd165
Kaplan, G. A., Turrell, G., Lynch, J. W., Everson, S. A., Helkala, E.-L. L., and Salonen, J. T. (2001). Childhood socioeconomic position and cognitive function in adulthood. Int. J. Epidemiol. 30, 256-263. doi: 10.1093/ije/ 30.2.256

Karsten, C. A., and Baram, T. Z. (2013). How does a neuron "know" to modulate its epigenetic machinery in response to early-life environment/experience? Front. Psychiatry 4:89. doi: 10.3389/fpsyt.2013.00089

Ke, X., Fu, Q., Majnik, A., Cohen, S., Liu, Q., and Lane, R. (2018). Adverse early life environment induces anxiety-like behavior and increases expression of FKBP5 mRNA splice variants in mouse brain. Physiol. Genomics 50, 973-981. doi: 10.1152/physiolgenomics.00054.2018

Kessler, R. C., Demler, O., Frank, R. G., Olfson, M., Pincus, H. A., Walters, E. E., et al. (2005). Prevalence and treatment of mental disorders, 1990 to 2003. $N$. Engl. J. Med. 352, 2515-2523. doi: 10.1056/NEJMsa043266

Klengel, T., and Binder, E. B. (2015). Epigenetics of stress-related psychiatric disorders and gene $\times$ environment interactions. Neuron 86, 1343-1357. doi: 10.1016/j.neuron.2015.05.036

Koch, H., McCormack, K., Sanchez, M. M., and Maestripieri, D. (2014). The development of the hypothalamic-pituitary-adrenal axis in rhesus monkeys: effects of age, sex, and early experience. Dev. Psychobiol. 56, 86-95. doi: $10.1002 /$ dev. 21093

Kopala-Sibley, D. C., Cyr, M., Finsaas, M. C., Orawe, J., Huang, A., Tottenham, N., et al. (2018). Early childhood parenting predicts late childhood brain functional connectivity during emotion perception and reward processing. Child Dev. doi: 10.1111/cdev.13126 [Epub ahead of print].

Korosi, A., and Baram, T. Z. (2009). The pathways from mother's love to baby's future. Front. Behav. Neurosci. 3:27. doi: 10.3389/neuro.08.027.2009

Korosi, A., Shanabrough, M., McClelland, S., Liu, Z.-W., Borok, E., Gao, X.-B., et al. (2010). Early-life experience reduces excitation to stress-responsive hypothalamic neurons and reprograms the expression of corticotropinreleasing hormone. J. Neurosci. 30, 703-713. doi: 10.1523/JNEUROSCI.421409.2010

Krugers, H. J., Arp, J. M., Xiong, H., Kanatsou, S., Lesuis, S. L., Korosi, A., et al. (2017). Early life adversity: lasting consequences for emotional learning. Neurobiol. Stress 6, 14-21. doi: 10.1016/j.ynstr.2016.11.005

Kundakovic, M., and Champagne, F. A. (2015). Early-life experience, epigenetics and the developing brain. Neuropsychopharmacology 40, 141-153. doi: $10.1038 / \mathrm{npp} .2014 .140$

Lesuis, S. L., Weggen, S., Baches, S., Lucassen, P. J., and Krugers, H. J. (2018). Targeting glucocorticoid receptors prevents the effects of early life stress on amyloid pathology and cognitive performance in APP/PS1 mice. Transl. Psychiatry 8:53. doi: 10.1038/s41398-018-0101-2

Levine, S. (1957). Infantile experience and resistance to physiological stress. Science 126:405. doi: 10.1126/science.126.3270.405

Liu, D., Diorio, J., Tannenbaum, B., Caldji, C., Francis, D., Freedman, A., et al. (1997). Maternal care, hippocampal glucocorticoid receptors and hypothalamic-pituitary-adrenal responses to stress. Science 277, 1659-1662. doi: 10.1126/science.277.5332.1659

Loi, M., Sarabdjitsingh, R. A., Tsouli, A., Trinh, S., Arp, M., Krugers, H. J., et al. (2017). Transient prepubertal mifepristone treatment normalizes deficits in contextual memory and neuronal activity of adult male rats exposed to maternal deprivation. eNeuro 4:ENEURO.0253-17.2017. doi: 10.1523/eneuro. 0253-17.2017

Lucassen, P. J., Naninck, E. F. G. G., van Goudoever, J. B., Fitzsimons, C., Joels, M., and Korosi, A. (2013). Perinatal programming of adult hippocampal structure and function: emerging roles of stress, nutrition and epigenetics. Trends Neurosci. 36, 621-631. doi: 10.1016/j.tins.2013.08.002

Ma, X.-M., and Lightman, S. L. (1998). The arginine vasopressin and corticotrophin-releasing hormone gene transcription responses to varied frequencies of repeated stress in rats. J. Physiol. 510, 605-614. doi: 10.1111/j. 1469-7793.1998.605bk.x

McClelland, S., Korosi, A., Cope, J., Ivy, A., and Baram, T. Z. (2011). Emerging roles of epigenetic mechanisms in the enduring effects of early-life stress and experience on learning and memory. Neurobiol. Learn. Mem. 96, 79-88. doi: 10.1016/j.nlm.2011.02.008

McEwen, B. S., Nasca, C., and Gray, J. D. (2016). Stress effects on neuronal structure: hippocampus, amygdala, and prefrontal cortex. Neuropsychopharmacology 41, 3-23. doi: 10.1038/npp.2015.171 
Meaney, M. J., Aitken, D. H., Bodnoff, S. R., Iny, L. J., Tatarewicz, J. E., and Sapolsky, R. M. (1985). Early postnatal handling alters glucocorticoid receptor concentrations in selected brain regions. Behav. Neurosci. 99, 765-770. doi: 10.1037//0735-7044.99.4.765

Molet, J., Heins, K., Zhuo, X., Mei, Y. T., Regev, L., Baram, T. Z., et al. (2016a). Fragmentation and high entropy of neonatal experience predict adolescent emotional outcome. Transl. Psychiatry 6:e702. doi: 10.1038/tp. 2015.200

Molet, J., Maras, P. M., Kinney-Lang, E., Harris, N. G., Rashid, F., Ivy, A. S., et al. (2016b). MRI uncovers disrupted hippocampal microstructure that underlies memory impairments after early-life adversity. Hippocampus 26, 1618-1632. doi: 10.1002/hipo.22661

Molet, J., Maras, P. M., Avishai-Eliner, S., and Baram, T. Z. (2014). Naturalistic rodent models of chronic early-life stress. Dev. Psychobiol. 56, 1675-1688. doi: 10.1002/dev.21230

Moriceau, S., Shionoya, K., Jakubs, K., and Sullivan, R. M. (2009). Early-life stress disrupts attachment learning: the role of amygdala corticosterone, locus ceruleus corticotropin releasing hormone and olfactory bulb norepinephrine. J. Neurosci. 29, 15745-15755. doi: 10.1523/jneurosci.4106-09.2009

Naninck, E. F. G., Hoeijmakers, L., Kakava-Georgiadou, N., Meesters, A., Lazic, S. E., Lucassen, P. J., et al. (2014). Chronic early life stress alters developmental and adult neurogenesis and impairs cognitive function in mice. Hippocampus 25, 309-328. doi: 10.1002/hipo.22374

Nelson, C. A., Bos, K., Gunnar, M. R., and Sonuga-Barke, E. J. S. (2011). The neurobiological toll of early human deprivation. Monogr. Soc. Res. Child Dev. 76, 127-146. doi: 10.1111/j.1540-5834.2011.00630.x

Nestler, E. J. (2014). Epigenetic mechanisms of depression. JAMA Psychiatry 71, 454-456. doi: 10.1001/jamapsychiatry.2013.4291

Neumann, I. D., and Slattery, D. A. (2016). Oxytocin in general anxiety and social fear: a translational approach. Biol. Psychiatry 79, 213-221. doi: 10.1016/j. biopsych.2015.06.004

Peña, C. J., Kronman, H. G., Walker, D. M., Cates, H. M., Bagot, R. C., Purushothaman, I., et al. (2017). Early life stress confers lifelong stress susceptibility in mice via ventral tegmental area OTX2. Science 356, 1185-1188. doi: $10.1126 /$ science.aan4491

Peña, C. J., Neugut, Y. D., Calarco, C. A., and Champagne, F. A. (2014). Effects of maternal care on the development of midbrain dopamine pathways and reward-directed behavior in female offspring. Eur. J. Neurosci. 39, 946-956. doi: 10.1111/ejn.12479

Plotsky, P. M., and Meaney, M. J. (1993). Early, postnatal experience alters hypothalamic corticotropin-releasing factor (CRF) mRNA, median eminence CRF content and stress-induced release in adult rats. Mol. Brain Res. 18, 195-200. doi: 10.1016/0169-328x(93)90189-v

Pollak, S. D., Nelson, C. A., Schlaak, M. F., Roeber, B. J., Wewerka, S. S., Wiik, K. L., et al. (2010). Neurodevelopmental effects of early deprivation in postinstitutionalized children. Child Dev. 81, 224-236. doi: 10.1111/j.14678624.2009.01391.x

Posner, J., Cha, J., Roy, A. K., Peterson, B. S., Bansal, R., Gustafsson, H. C., et al. (2016). Alterations in amygdala-prefrontal circuits in infants exposed to prenatal maternal depression. Transl. Psychiatry 6:e935. doi: 10.1038/tp. 2016.146

Regev, L., Neufeld-Cohen, A., Tsoory, M., Kuperman, Y., Getselter, D., Gil, S., et al. (2011). Prolonged and site-specific over-expression of corticotropin-releasing factor reveals differential roles for extended amygdala nuclei in emotional regulation. Mol. Psychiatry 16, 714-728. doi: 10.1038/mp.2010.64

Regev, L., Tsoory, M., Gil, S., and Chen, A. (2012). Site-specific genetic manipulation of amygdala corticotropin-releasing factor reveals its imperative role in mediating behavioral response to challenge. Biol. Psychiatry 71, 317-326. doi: 10.1016/j.biopsych.2011.05.036

Rice, C. J., Sandman, C. A., Lenjavi, M. R., and Baram, T. Z. (2008). A novel mouse model for acute and long-lasting consequences of early life stress. Endocrinology 149, 4892-4900. doi: 10.1210/en.2008-0633

Rincón-Cortés, M., and Sullivan, R. M. (2014). Early life trauma and attachment: immediate and enduring effects on neurobehavioral and stress axis development. Front. Endocrinol. 5:33. doi: 10.3389/fendo.2014. 00033

Ross, D. A., Arbuckle, M. R., Travis, M. J., Dwyer, J. B., van Schalkwyk, G. I., and Ressler, K. J. (2017). An integrated neuroscience perspective on formulation and treatment planning for posttraumatic stress disorder. JAMA Psychiatry 74 , 407-415. doi: 10.1001/jamapsychiatry.2016.3325

Russo, S. J., Murrough, J. W., Han, M.-H. H., Charney, D. S., and Nestler, E. J. (2012). Neurobiology of resilience. Nat. Neurosci. 15, 1475-1484. doi: $10.1038 / \mathrm{nn} .3234$

Rutledge, R. B., Skandali, N., Dayan, P., and Dolan, R. J. (2014). A computational and neural model of momentary subjective well-being. Proc. Natl. Acad. Sci. US A 111, 12252-12257. doi: 10.1073/pnas.1407535111

Schmidt, M. V., Abraham, W. C., Maroun, M., Stork, O., and Richter-Levin, G. (2013). Stress-induced metaplasticity: from synapses to behavior. Neuroscience 250, 112-120. doi: 10.1016/j.neuroscience.2013.06.059

Schulmann, A., Bolton, J. L., Curran, M. M., Regev, L., Kamei, N., Singh-Taylor, A., et al. (2018). Blocking NRSF function rescues spatial memory impaired by early-life adversity and reveals unexpected underlying transcriptional programs. SSRN Electron. J. doi: 10.2139/ssrn.3284454

Schwaiger, M., Grinberg, M., Moser, D., Zang, J. C. S., Heinrichs, M., Hengstler, J. G., et al. (2016). Altered stress-induced regulation of genes in monocytes in adults with a history of childhood adversity. Neuropsychopharmacology 41, 2530-2540. doi: 10.1038/npp.2016.57

Seay, B., Hansen, E., and Harlow, H. F. (1962). Mother-infant separation in monkeys. J. Child Psychol. Psychiatry 3, 123-132. doi: 10.1111/j.1469-7610. 1962.tb02047.x

Segman, R. H., Shefi, N., Goltser-Dubner, T., Friedman, N., Kaminski, N., and Shalev, A. Y. (2005). Peripheral blood mononuclear cell gene expression profiles identify emergent post-traumatic stress disorder among trauma survivors. Mol. Psychiatry 10, 500-513. doi: 10.1038/sj.mp.40 01636

Seth, K. A., and Majzoub, J. A. (2001). Repressor element silencing transcription factor/neuron-restrictive silencing factor (REST/NRSF) can act as an enhancer as well as a repressor of corticotropin-releasing hormone gene transcription. J. Biol. Chem. 276, 13917-13923. doi: 10.1074/jbc.m0077 45200

Singh-Taylor, A., Molet, J., Jiang, S., Korosi, A., Bolton, J. L., Noam, Y., et al. (2018). NRSF-dependent epigenetic mechanisms contribute to programming of stress-sensitive neurons by neonatal experience, promoting resilience. Mol. Psychiatry 23, 648-657. doi: 10.1038/mp.2016.240

Suderman, M., Borghol, N., Pappas, J. J., Pinto Pereira, S. M., Pembrey, M., Hertzman, C., et al. (2014). Childhood abuse is associated with methylation of multiple loci in adult DNA. BMC Med. Genomics 7:13. doi: 10.1186/17558794-7-13

Szyf, M., Tang, Y.-Y., Hill, K. G., and Musci, R. (2016). The dynamic epigenome and its implications for behavioral interventions: a role for epigenetics to inform disorder prevention and health promotion. Transl. Behav. Med. 6 , 55-62. doi: 10.1007/s13142-016-0387-7

van Bodegom, M., Homberg, J. R., and Henckens, M. J. A. G. (2017). Modulation of the hypothalamic-pituitary-adrenal axis by early life stress exposure. Front. Cell. Neurosci. 11:87. doi: 10.3389/fncel.2017.00087

Ventura, R., Coccurello, R., Andolina, D., Latagliata, E. C., Zanettini, C., Lampis, V., et al. (2013). Postnatal aversive experience impairs sensitivity to natural rewards and increases susceptibility to negative events in adult life. Cereb. Cortex 23, 1606-1617. doi: 10.1093/cercor/bhs145

Voorn, P., Kalsbeek, A., Jorritsma-Byham, B., and Groenewegen, H. J. (1988). The pre- and postnatal development of the dopaminergic cell groups in the ventral mesencephalon and the dopaminergic innervation of the striatum of the rat. Neuroscience 25, 857-887. doi: 10.1016/0306-4522(88)90041-3

Wakeford, A. G. P., Morin, E. L., Bramlett, S. N., Howell, L. L., and Sanchez, M. M. (2018). A review of nonhuman primate models of early life stress and adolescent drug abuse. Neurobiol. Stress 9, 188-198. doi: 10.1016/j.ynstr.2018. 09.005

Walker, C.-D., Bath, K. G., Joels, M., Korosi, A., Larauche, M., Lucassen, P. J., et al. (2017). Chronic early life stress induced by limited bedding and nesting (LBN) material in rodents: critical considerations of methodology, outcomes and translational potential. Stress 20, 421-448. doi: 10.1080/10253890.2017. 1343296

Wang, X.-D., Rammes, G., Kraev, I., Wolf, M., Liebl, C., Scharf, S. H., et al. (2011). Forebrain $\mathrm{CRF}_{1}$ modulates early-life stress-programmed cognitive deficits. J. Neurosci. 31, 13625-13634. doi: 10.1523/JNEUROSCI.225911.2011 
Weaver, I. C., Cervoni, N., Champagne, F. A., D’Alessio, A. C., Sharma, S., Seckl, J. R., et al. (2004). Epigenetic programming by maternal behavior. Nat. Neurosci. 7, 847-854. doi: 10.1038/nn1276

Xu, J., Wang, R., Liu, Y., Liu, D., Jiang, H., and Pan, F. (2017). FKBP5 and specific microRNAs via glucocorticoid receptor in the basolateral amygdala involved in the susceptibility to depressive disorder in early adolescent stressed rats. J. Psychiatr. Res. 95, 102-113. doi: 10.1016/j.jpsychires.2017.08.010

Yehuda, R., Cai, G., Golier, J. A., Sarapas, C., Galea, S., Ising, M., et al. (2009). Gene expression patterns associated with posttraumatic stress disorder following exposure to the world trade center attacks. Biol. Psychiatry 66, 708-711. doi: 10.1016/j.biopsych.2009.02.034
Conflict of Interest Statement: The authors declare that the research was conducted in the absence of any commercial or financial relationships that could be construed as a potential conflict of interest.

Copyright (C) 2019 Bolton, Short, Simeone, Daglian and Baram. This is an open-access article distributed under the terms of the Creative Commons Attribution License (CC BY). The use, distribution or reproduction in other forums is permitted, provided the original author(s) and the copyright owner(s) are credited and that the original publication in this journal is cited, in accordance with accepted academic practice. No use, distribution or reproduction is permitted which does not comply with these terms. 